PREPARED FOR THE U.S. DEPARTMENT OF ENERGY, UNDER CONTRACT DE-AC02-76CH03073

PPPL-3606

PPPL-3606

UC-70

Studies of Non-conventional Configuration Closed Electron Drift Thrusters

by

Y. Raitses, D. Staack, A. Smirnov, A.A. Litvak, L.A. Dorf, T. Graves, and N.J. Fisch

September 2001

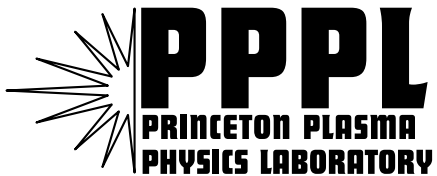

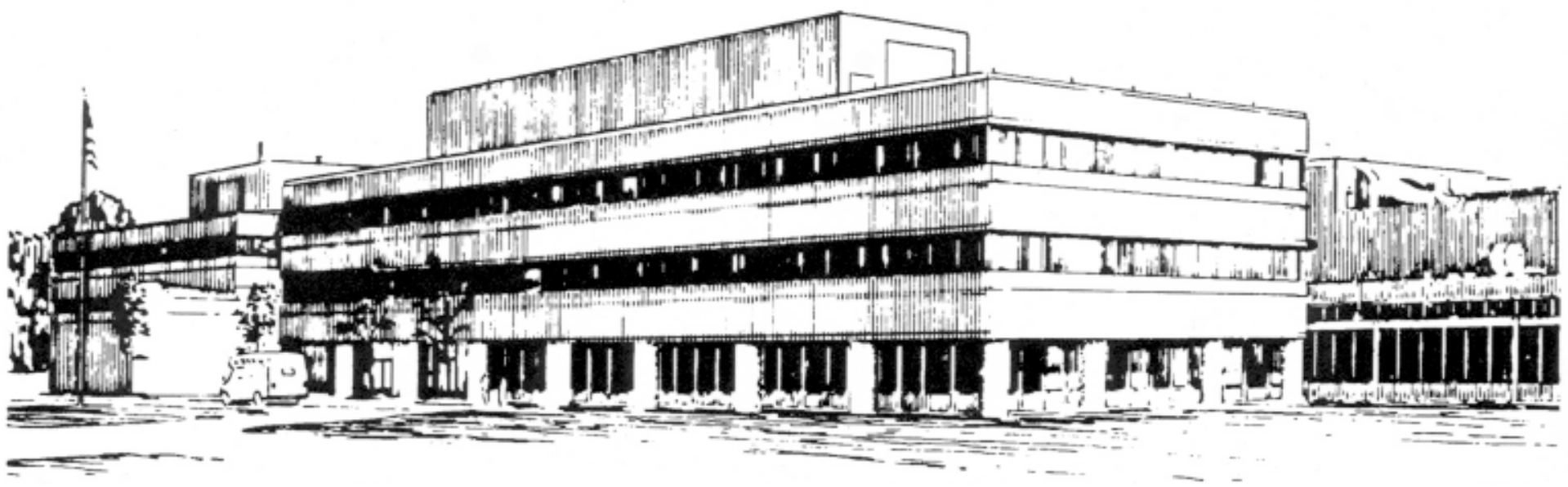

PRINCETON PLASMA PHYSICS LABORATORY PRINCETON UNIVERSITY, PRINCETON, NEW JERSEY 


\section{PPPL Reports Disclaimer}

This report was prepared as an account of work sponsored by an agency of the United States Government. Neither the United States Government nor any agency thereof, nor any of their employees, makes any warranty, express or implied, or assumes any legal liability or responsibility for the accuracy, completeness, or usefulness of any information, apparatus, product, or process disclosed, or represents that its use would not infringe privately owned rights. Reference herein to any specific commercial product, process, or service by trade name, trademark, manufacturer, or otherwise, does not necessarily constitute or imply its endorsement, recommendation, or favoring by the United States Government or any agency thereof. The views and opinions of authors expressed herein do not necessarily state or reflect those of the United States Government or any agency thereof.

\section{Availability}

This report is posted on the U.S. Department of Energy's Princeton Plasma Physics Laboratory Publications and Reports web site in Calendar Year 2001. The home page for PPPL Reports and Publications is: http://www.pppl.gov/pub_report/

DOE and DOE Contractors can obtain copies of this report from:

U.S. Department of Energy

Office of Scientific and Technical Information

DOE Technical Information Services (DTIS)

P.O. Box 62

Oak Ridge, TN 37831

Telephone: (865) 576-8401

Fax: (865) 576-5728

Email: reports@adonis.osti.gov

This report is available to the general public from:

National Technical Information Service

U.S. Department of Commerce

5285 Port Royal Road

Springfield, VA 22161

Telephone: 1-800-553-6847 or

(703) 605-6000

Fax: (703) 321-8547

Internet: http://www.ntis.gov/ordering.htm 


\title{
Studies of Non-Conventional Configuration Closed Electron Drift Thrusters
}

\author{
Y. Raitses, D. Staack, A. Smirnov, A. A. Litvak, L. A. Dorf, T. Graves and N. J. Fisch \\ Princeton University Plasma Physics Laboratory \\ P. O. Box 451, Princeton, NJ 08543
}

\begin{abstract}
$\underline{\text { Abstract }}$
In this paper we review recent results obtained for segmented electrode and cylindrical Hall thrusters. A low sputtering graphite segmented electrode, placed at the exit of the annular thruster, is shown to affect the plasma potential distribution in the ceramic channel. This effect appears to be correlated with an observed plume reduction compared to a conventional, nonsegmented thruster. In preliminary experiments a $3 \mathrm{~cm}$ thruster was operated in the 50-200 W power range. Two operating regimes, stable and oscillating, were observed and investigated.
\end{abstract}

\section{Introduction}

A conventional Hall thruster is a crossed field discharge device with a coaxial channel, in which an electrostatic acceleration of ions takes place in quasi-neutral plasma. A significant axial electric field is established in the vicinity of the maximum radial magnetic field, typically near the thruster exhaust. The length of the acceleration region and its location relative to the magnetic field distribution depends mainly on the electron mobility and can be strongly affected by material properties of the channel walls, namely, conductivity and secondary electron emission [1]. However, a simple exchange of the channel materials, for example, from ceramic to metal, does not necessarily lead to changes in the beam divergence. The beam divergence is affected by electron pressure gradients and the fringing magnetic field [2]. As a result of large beam divergence, existing Hall thrusters are limited in terms of performance, integration with spacecraft and thruster lifetime.

As an alternative to the conventional use of a channel made from either ceramic or metal, a segmented electrode Hall thruster, which was

Copyright @ 2001 by the American Institute of Aeronautics and Astronautics Inc. All rights reserved suggested and studied in refs. [3-6] uses emissive or low emissive electrodes placed along a ceramic channel in order to control the electric field and localize the acceleration between the electrodes. The results obtained with low emissive electrodes demonstrated a plume reduction of about $20 \%$ compared to a conventional non-segmented thruster configuration $[4,5]$. In this paper we continue studies of this effect by comparing the plasma potential distribution measured in conventional and segmented electrode configurations.

Another possible way to reduce the negative effect of the beam divergence can be achieved in a cylindrical geometry Hall thruster with a cusp magnetic field. This thruster, which can be useful for miniaturization, has no inner parts and therefore, less wall and power losses in the channel. A relatively large $9 \mathrm{~cm}$ diameter version of this thruster already demonstrated performance comparable with conventional annular Hall thrusters in the sub-kilowatt power range [7]. Here, we describe recent measurements of a miniaturized $3 \mathrm{~cm}$ diameter cylindrical Hall thruster, which was successfully operated in the $50-300 \mathrm{~W}$ power range.

\section{Experiments with Segmented Electrode Hall Thruster}

\section{Thruster and electrode}

The $9 \mathrm{~cm}$ laboratory Hall thruster and test facility used in this study has been described in refs. [3-5]. Fig. 1 shows this thruster with a 4 $\mathrm{mm}$ length segmented electrode, which is placed on the inner channel wall near the thruster exit. The segmented electrode is made from a carboncarbon-fiber graphite material, which has the lowest sputtering yield; less than $10^{-3}$ atoms/ion in Xenon plasmas at ion energies of below 400 $\mathrm{eV}$ [8]. The reason for the use of a low sputtering electrode material is to avoid a conductive coating of the outer channel wall, which had 
been observed in our previous experiments with Tantalum [3] and $\mathrm{LaB}_{6}$ electrodes [4,5]. The placement of the graphite segmented electrode relative to the magnetic field distribution is shown in Fig. 2.

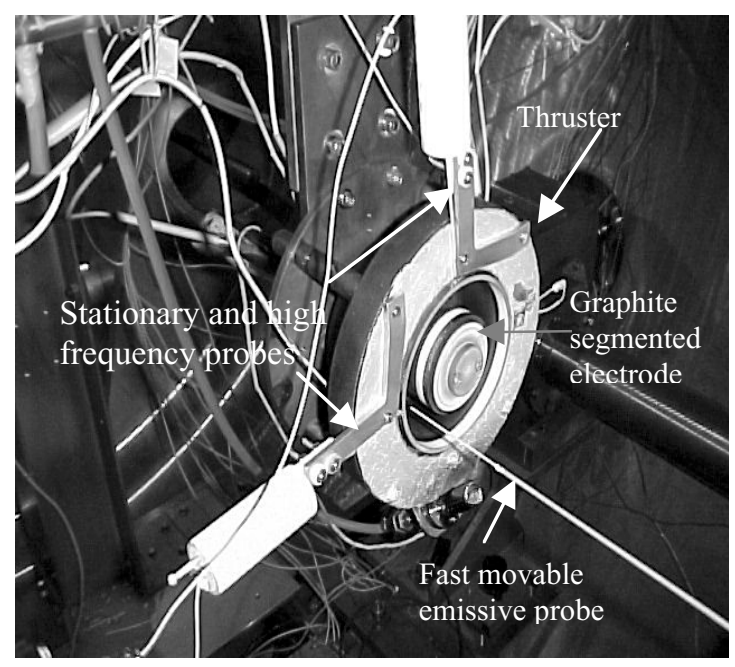

Fig. 1 Segmented electrode Hall thruster and probe setup

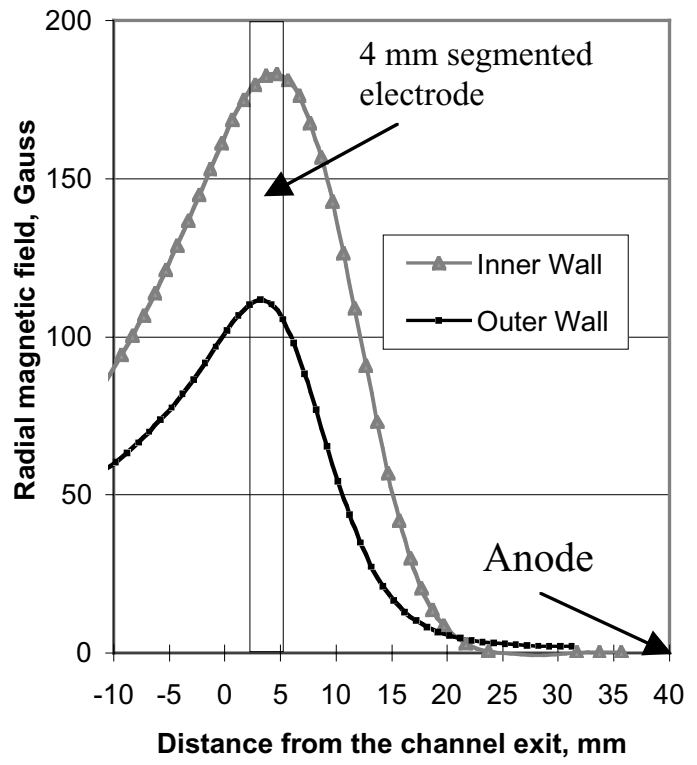

Fig. 2 Magnetic field distribution and placement of the graphite segmented electrode.

In our previous studies this position of the segmented electrode (referred to as NS2) gave maximum plume reduction for the discharge voltages in the range of 200-270 V [4].

\section{Diagnostic setup}

In these experiments, we used a fast movable emissive probe setup to measure the plasma potential distribution inside the thruster channel (Fig. 1). The emissive probe design is shown in Fig. 3. It consists of a $1.18 \mathrm{~mm}$ diameter double bore alumina tube surrounded by a $1.5 \mathrm{~mm}$ diameter molybdenum shield. A $0.25 \mathrm{~mm}$ tungsten wire passes through the alumina and is electrolytically etched to $0.1 \mathrm{~mm}$ at the probe tip to form a filament. The floating potential of the probe relative to the ground was measured using a 1:100 isolating amplifier and monitored by a PC-based data acquisition system.

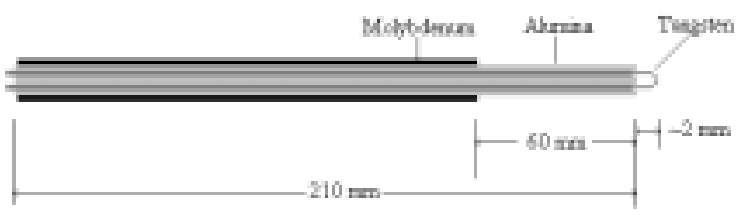

Fig. 3 Floating emissive probe design.

The probe positioning system consists of a Normag linear motor with a maximum speed of $1 \mathrm{~m} / \mathrm{s}$ assembled on a relatively slow Velmex linear gear motor. The fast positioner provides probe motion in the axial direction at different radial locations determined by the Velmex positioner. The axial position of the probe is measured by a Rensishaw optical encoder with 20 micron resolution. Control and measurement of this positioning system is performed by a PCbased data acquisition system. Fig. 4 shows illustrative profiles of the residence time and the probe immersion speed versus the probe location during the acquisition time. In order to monitor possible plasma perturbations induced by the movable probe $[9,10]$, the discharge current was simultaneously monitored by the data acquisition system during the probe movement.

Other measurements included mass flow rate, discharge current and voltage, electromagnetic coils current, potential of the floating segmented electrode relative to the ground and current to the cathode biased electrode. Also the angular ion flux distribution was measured by a movable flat Langmuir probe with a guarding sleeve [3]. 


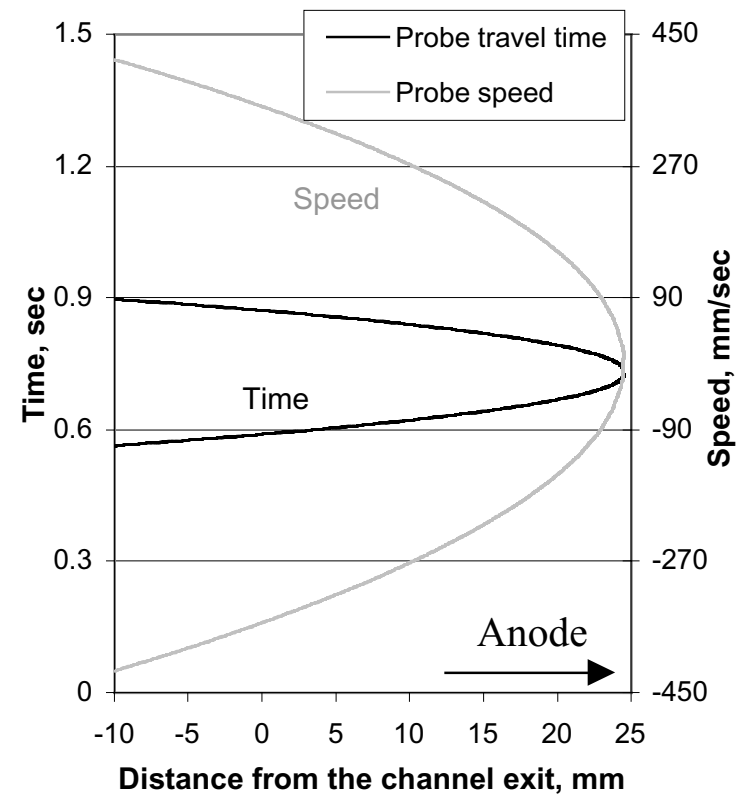

Fig. 4 Dynamic characteristics of the probe positioning system.

\section{Experimental procedure}

The measurements of the plasma potential in conventional and segmented electrode thruster configurations were performed at the same operating conditions, namely, discharge voltage of $250 \mathrm{~V}$ and xenon gas flow rate of $1.7 \mathrm{mg} / \mathrm{s}$ and a constant magnetic field. In order to provide stable operation we maintained different currents in the inner and outer electromagnetic coils of the thruster.

After the thruster reached steady state, the angular ion flux distribution was measured and integrated to obtain the total ion flux and the plume angle for $90 \%$ of the total ion flux [4]. After that, the fast probe was introduced into the channel first near its outer wall with no heating and then with gradually increased heating. At operational heating power, the probe reached saturation values of its floating potential along its trajectory. Keeping this power constant, the probe measurements were repeated several times to characterize reproducibility and estimate average profiles. Next, the probe position was changed in the radial direction and the procedure was repeated. In each thruster configuration potential profiles were measured for 9 radial positions of the probe.

In general, reproducibility of probe measurements was not less than $85 \%$. The major source of irreproducibility was probe-induced perturbations of the thruster discharge, which tended to increase and then saturate as the probe moved toward the anode (Fig. 5). The amplitude of the discharge current perturbations could reach $50 \%$ of its steady state value. These perturbations appear less than $0.1 \mathrm{sec}$ after the probe immersion and are more substantial at the channel median than near the outer and inner walls. Therefore, it is not clear if they result from probe heating and ablation by electron Hall current [10] or by some other mechanisms (see for example in [11]). For example, using a stationary probe placed on the outer channel wall, we observed indications on some outward shift of the acceleration region as the fast probe moved towards the anode [12]

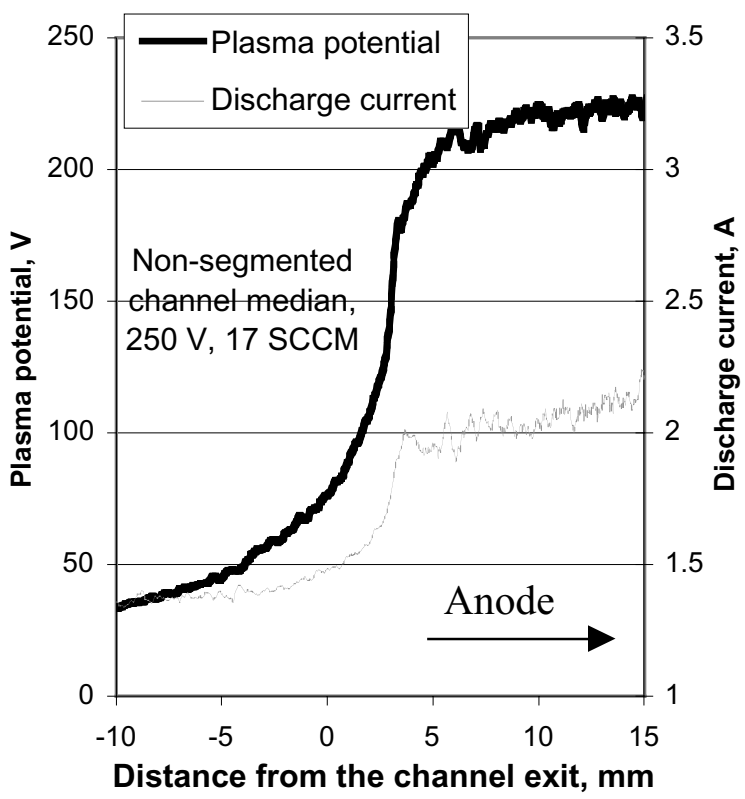

Fig. 5 Plasma potential distribution measured by fast emissive probe relative to the ground and probe induced perturbations of the discharge current.

Note that in addition to perturbations, uncertainties of the emissive probe measurements include a voltage drop across the filament produced by the dc heating power supply $(\sim 10 \mathrm{~V})$ and a double sheath formed between hot floating probe and plasma $\left(\Delta \varphi \approx T_{e}\right)$ [13]. 


\section{Experimental results}

Table 1 lists integral parameters measured for three different thruster configurations, nonsegmented, segmented biased and segmented floating. Note that the results obtained with floating and biased segmented electrodes are different from those reported in refs. [3,4] for segmented electrodes made from Tantalum and $\mathrm{LaB}_{6}$. For example, the discharge current in the graphite electrode case is, in general, smaller and less affected by the applied bias. In addition, the collecting current to the biased segmented electrode is also smaller.

Table 1: Integral thruster parameters for conventional and segmented configurations.

\begin{tabular}{|l|c|c|c|}
\hline Thruster & Non- & \multicolumn{2}{|c|}{ Segmented } \\
Config.: & segmented & Floating & Biased \\
\hline $\mathrm{I}_{\mathrm{d}}, \mathrm{A}$ & $1.56-1.57$ & $1.59-1.6$ & $1.62-1.65$ \\
$\mathrm{~V}_{\mathrm{fl}}, \mathrm{V}$ & - & $17-22$ & 0 \\
$\mathrm{I}_{\mathrm{seg}}, \mathrm{mA}$ & - & 0 & $56-60$ \\
\hline
\end{tabular}

Finally, the total ion flux from the thruster was almost unchanged in all three thruster configurations, while a plume angle reduction obtained with this electrode relative to the nonsegmented thruster configuration was not more than $10 \mathrm{deg}$, i.e. less than a half of what was reported in ref. [4] for a different magnetic field distribution produced by the electromagnetic coils connected in series in the same thruster. Note that use of different electrode materials might also cause the observed differences. For example, in a recent set of experiments with an additional graphite segmented electrode placed on the outer wall near the thruster exit, we observed a plume angle reduction of about 20 deg, with the inner wall electrode cathode biased. This additional electrode may have served as the equivalent to a conductive coating, which was typically observed in experiments with metal electrodes as a result of their sputtering by ion bombardment [3-5]. The effect of this outer electrode on the plume and its relevance to the referenced results is currently being investigated.

Remarkably, the location of the acceleration and ionization region relative to the magnetic field distribution is substantially affected by the single segmented electrode (Figs. 6, 7). It moves a few millimeters upstream of the channel as compared to non-segmented thruster configuration. As a result, there is a relatively smaller fraction of the voltage drop left outside the thruster channel in the fringing magnetic field. In conventional configuration, about $40-50 \%$ of the measured voltage drop is outside the thruster channel. This is in agreement with results of refs. [9,14]. Note that the bias of the segmented electrode does not substantially change the potential profile as compared to the floating segmented electrode case.

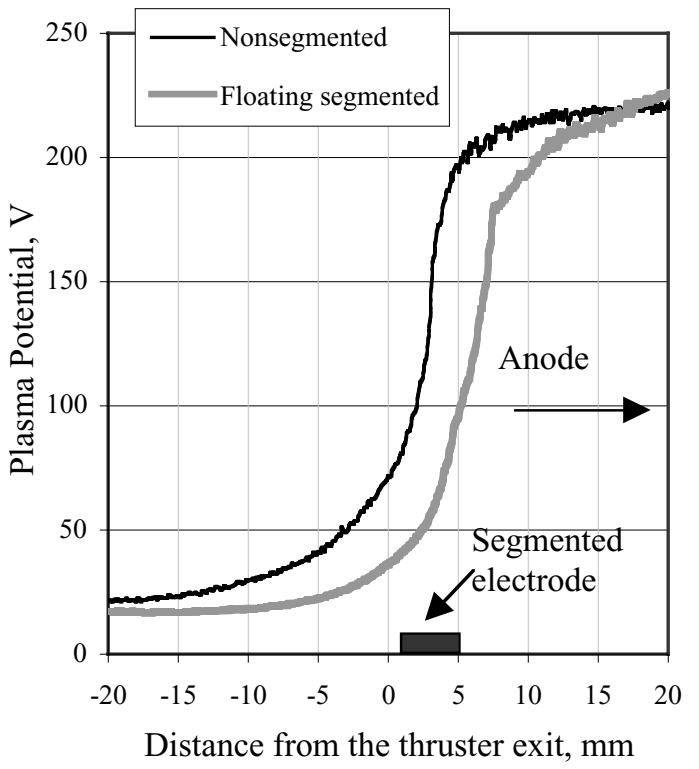

Fig. 6 Plasma potential profiles measured for segmented and non segmented thruster configurations along the channel median.

One explanation of these results is as follows. Since in both the floating and biased cases, the electrode potential is more negative than the plasma bulk, it collects the ions from the plasma, smoothing the voltage potential distribution along the conductive electrode and making the plasma potential more negative. In this respect, the electrode-collector acts similarly to an emissive electrode emitting electrons from its equipotential surface along magnetic field lines $[3,6,13]$. Most of the voltage drop is still established in a strong magnetic field, but upstream of the segmented electrode. Alternatively, the observed plume reduction may also be related to the localization of the acceleration region in the concave focusing magnetic field. 

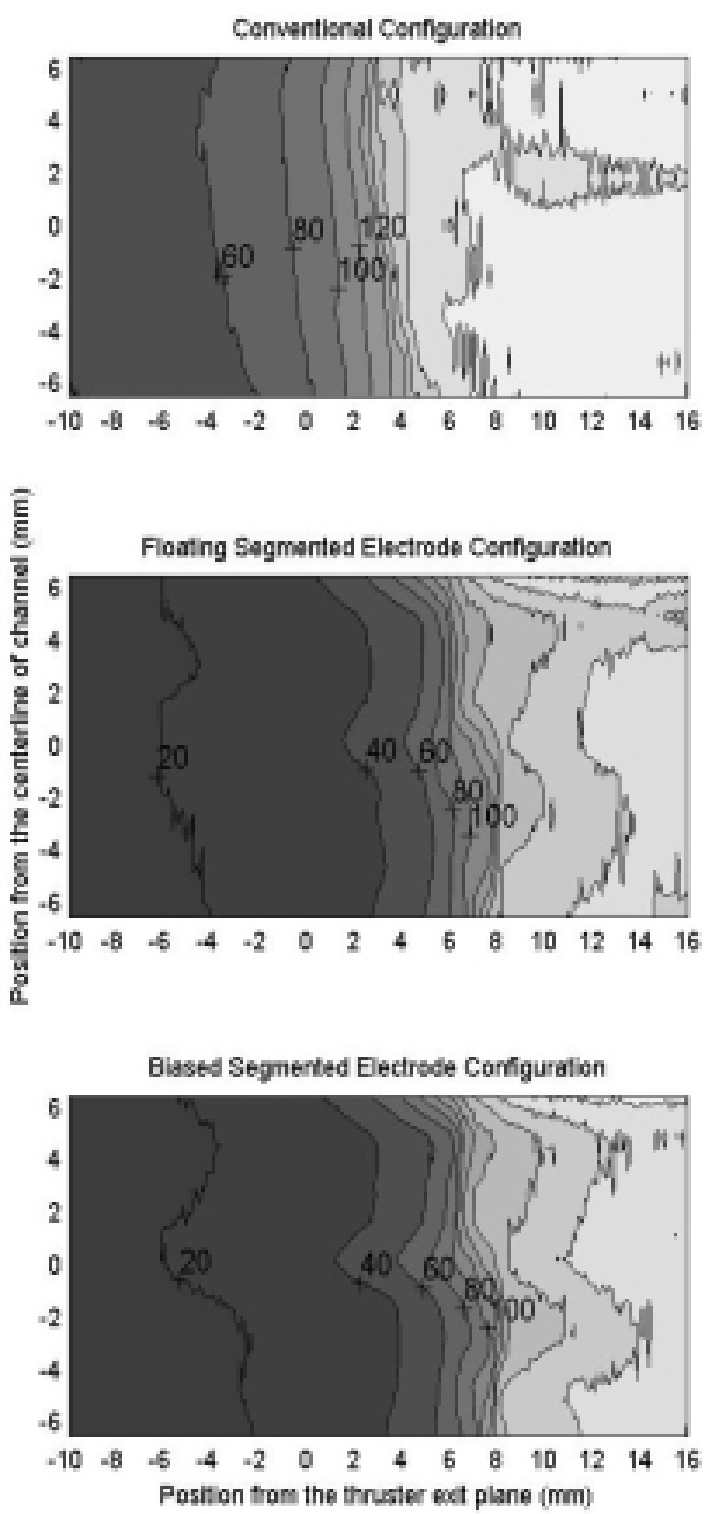

Fig. 7 Plasma potential contours (20 V step) obtained for three thruster configurations, non segmented, segmented floating and segmented biased at discharge voltage of $250 \mathrm{~V}$ and mass flow rate of $1.7 \mathrm{mg} / \mathrm{s}$. Note that irregularities at larger potentials and along the channel median (segmented cases) may be caused by probe induced perturbations of the plasma.

In the first explanation above we assumed that the electrode drives enough ion current to affect the plasma potential in the whole channel. However, it is not clear if the relatively small current measured in the segmented electrode circuit is enough for the observed changes.
Perhaps, there are also other phenomena such as secondary electron emission and near wall conductivity involved in the effect of segmented electrodes. According to ref. [2], in the thruster channel with metal walls, electron near wall conductivity across the magnetic field is smaller and, as a result, the acceleration region becomes shorter, localized at the thruster exit. Since quite the opposite effect was observed with the segmented electrode at the exit of ceramic channel, it seems that a precise location of the electrode relative to the magnetic field distribution and its dimensions can influence on the formation of the acceleration region either inside or outside the thruster channel.

\section{Preliminary Experiments with Small Cylindrical Hall Thruster}

\section{Experimental setup}

A $3 \mathrm{~cm}$ cylindrical Hall thruster shown in Fig. 8, was scaled down from a $9 \mathrm{~cm}$ cylindrical Hall thruster to operate at $\sim 200 \mathrm{~W}$ power level [7]. Similar to the large thruster, this miniaturized cylindrical thruster consists of a Boron Nitride ceramic channel, an annular anode, which is also a gas distributor, two electromagnetic coils, and a magnetic core. The overall diameter and length of the thruster are both, $7 \mathrm{~cm}$. A flexible design of this thruster allows variations of the thruster geometry.

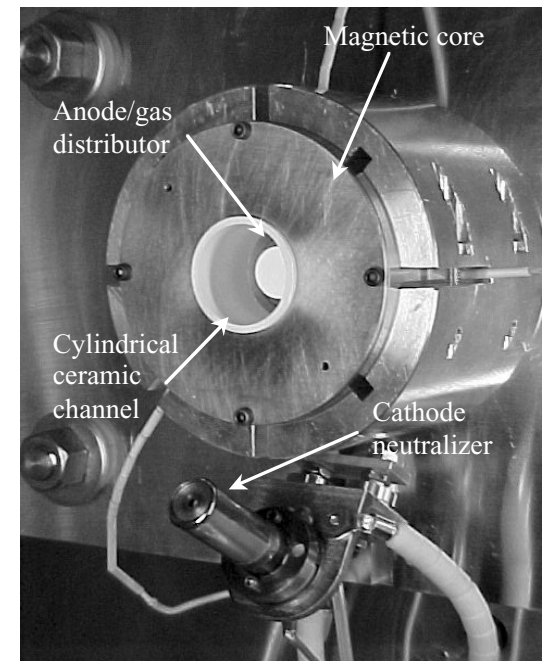

Fig. 8 A $3 \mathrm{~cm}$ cylindrical Hall thruster.

In this preliminary study we investigated two different thruster configurations, namely, conventional with an annular channel of $2.6 \mathrm{~cm}$ length, $2.6 \mathrm{~mm}$ OD diameter and $1.4 \mathrm{~cm}$ ID 
diameter, and cylindrical with the same OD and the channel length. The channel of the cylindrical thruster features a short annular region, approximately $1 \mathrm{~cm}$ long, and longer cylindrical region. Following the ref [7], the length of the annular region is selected in order to minimize $\lambda_{\text {ion }} / L$ and thus, providing the ionization of the working gas at the boundary of annular and cylindrical regions. The cylindrical region has larger volume to surface ratio, which should decrease power and ion losses, erosion of the thruster parts and heating, especially critical for the magnetic circuit.

Two electromagnetic coils are connected to separate power supplies. The currents in the coils are co-directed in conventional configuration and counter-directed in cylindrical configuration to produce cusp magnetic field with a strong radial component in the channel [7]. Fig. 9 shows the results of magnetic field simulations for the annular and cylindrical thrusters. The magnetic field was measured inside both these thrusters using a miniature Hall probe.

(a)

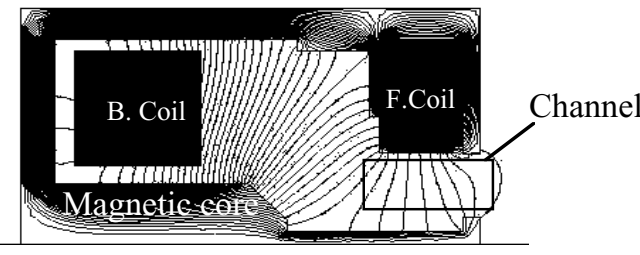

Thruster axis

(b)

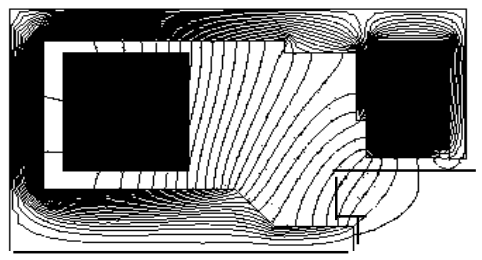

Thruster axis

Fig. 9 Magnetic circuit of the annular thruster (a) and cylindrical (b) thruster. The channel OD diameter is $2.6 \mathrm{~cm}$.

For example, for the operating currents of $1.4 \mathrm{~A}$ in the back coil and 0.9 ampere in the front coil, the maximum radial magnetic field is 300 Gauss near the exit of the annular thruster at the inner wall. In the cylindrical configuration, the radial magnetic field reaches the maximum, $\sim 450$ Gauss, a few millimeters from the anode near the inner wall of the short annular part and then reduces towards the thruster exit.
A commercial HeatWave plasma source was used as a cathode-neutralizer. This cathode was able to operate at xenon flow rate of $1.5-2 \mathrm{sccm}$ and sustain the thruster discharge current of 0.2 A with external heating and keeper.

The experiments took place in a $76 \mathrm{~cm}$ diameter and $91 \mathrm{~cm}$ length vacuum chamber, equipped with a turbo molecular pumping system. The measured pumping speed is about $320 \mathrm{l} / \mathrm{s}$ for xenon. At a xenon gas flow rate of 5 SCCM, the background pressure was not less than 0.2 millitorr. A research grade xenon gas is fed from a gas cylinder with a two-stage pressure regulator to anode and cathode. In order to smooth possible fluctuations of the pressure, a stagnation cylinder was included in the feed line between the regulator and flow controllers. Two commercial flow controllers, $0-10 \mathrm{sccm}$ and 0-15 sccm, volumetrically calibrated in the flow rate range of 1-5 sccm, were used for anode and cathode, respectively.

Diagnostics for this set of micro thruster experiments included $\mathrm{dc}$ and ac electrical measurements and ion flux by a collector biased $-30 \mathrm{~V}$ relative to the ground.

\section{Thruster operation and V-I characteristics}

The $3 \mathrm{~cm}$ Hall thruster was operated at the discharge voltages of $150-300 \mathrm{~V}$ and xenon mass flow rates of $2-4 \mathrm{mg} / \mathrm{s}$. Note that in these experiments the flow rate was constrained by the pumping capabilities of the vacuum system. As a result, the thruster was not operated at the designed level for the mass flow rates of $0.7-1$ $\mathrm{mg} / \mathrm{s}$. The cathode placement was near the thruster exit at the $90 \mathrm{deg}$ angle to the thruster axis. It was found that this placement enables an easier thruster start-up than shown in Fig. 8.

For both cylindrical and annular configurations, two qualitatively distinct regimes of operation, referred below to as unstable and stable, were observed in the measured range of the discharge voltage and the gas flow rate. The unstable regime is characterized by the presence of strong $1 \mathrm{kHz}$-range discharge current oscillations, while the stable regime is quiescent in this frequency range. Fig. 10 shows operation of the cylindrical thruster in these regimes. In addition, Fig. 11 shows typical traces of the discharge current in the unstable regime. Physical mechanisms, which could cause this unstable behavior, are 
currently being investigated. These include, for example, relaxation-type of instabilities, which should depend on the external electrical circuit. Since an increase of the gas flow rate usually switched the thruster to stable operating regimes, the instability may be affected by low mass flow rates used in these experiments.
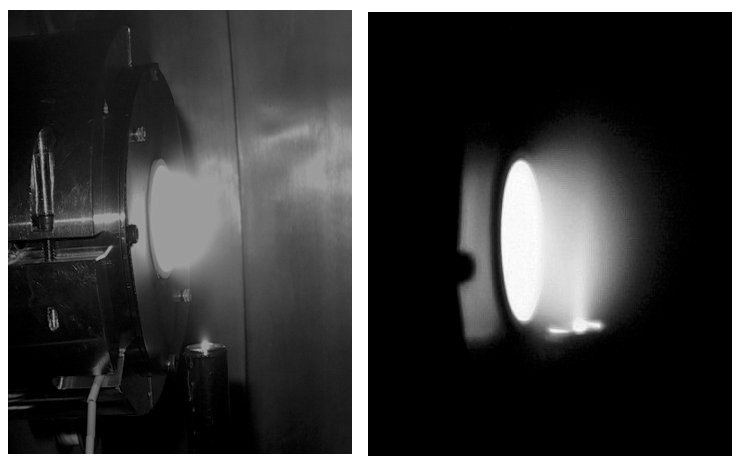

Fig. 10 Cylindrical thruster in stable (a) and unstable (b) operating regimes. The plume is visually more diffused in the unstable regime.

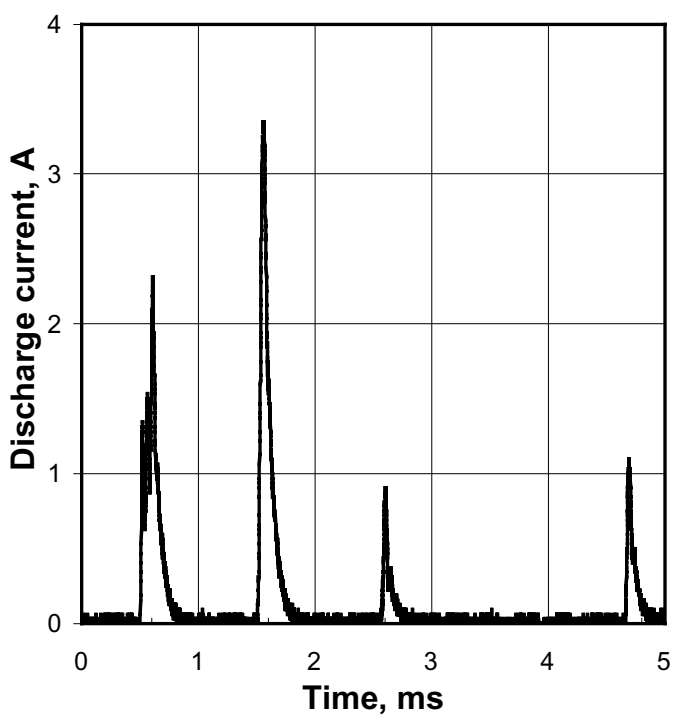

Fig. 11 A typical trace of the discharge current in the unstable regime.

Interestingly, depending on the initial conditions of the thruster start-up, the discharge can be brought to either stable or unstable regime with the same coil currents, discharge voltage, and cathode and anode gas flows. The physical phenomena behind this bifurcation is not clear.

In stable operating regimes, the dependence of the discharge current on the magnetic field is similar to large conventional Hall thrusters. As can be seen in Fig. 12, there exists an optimal magnetic field at which the discharge current is minimal. An increase of the magnetic field above this optimal value affects discharge current oscillations of $\sim 50 \mathrm{kHz}$, Fig 13, which are probably related to ionization instabilities [15] in the scaled down thruster. With the cylindrical thruster, the difficulty sustaining a discharge, while adjusting the magnetic coil currents, was frequently experienced. As a result, it was not always possible to minimize the discharge current by varying the currents in the electromagnetic coils.

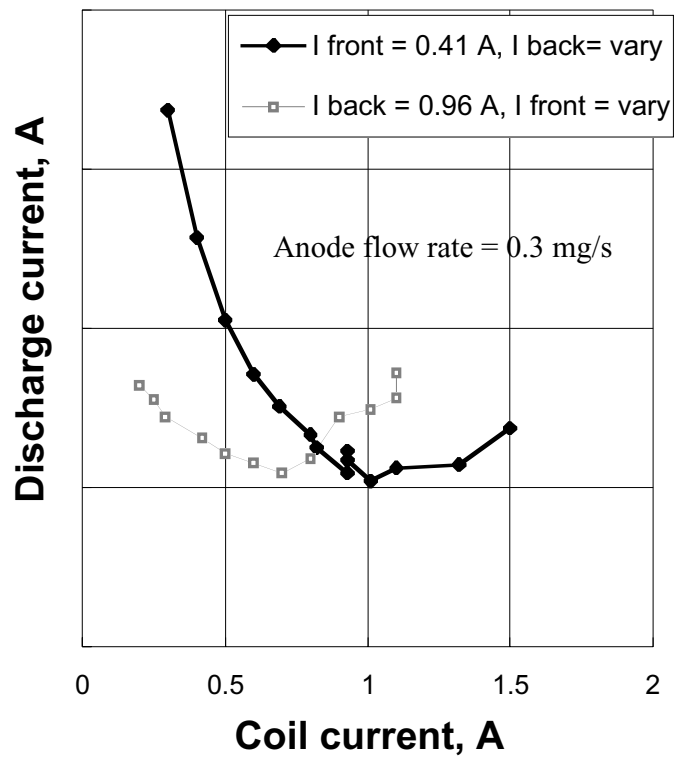

Fig. 12 The effect of the magnetic field on the discharge current for the annular $3 \mathrm{~cm}$ thruster.

Illustrative curves of voltage versus current characteristics measured in stable and unstable regimes for both thruster configurations are shown in Fig 14. Although the discharge current for the annular thruster in the stable regime is somewhat smaller than for the cylindrical, its ratio to the equivalent gas flow current corrected for the background pressure effect is almost 3 times higher than the corresponding ratios for large annular and cylindrical Hall thrusters, 1.1-1.5 [1,7]. Thus, there is a significant fraction of the axial electron current in the total discharge current for both miniaturized thruster configurations. In addition to the background gas effect and possible issues associated with heating of the magnetic circuit, non-uniform discharge structures observed in stable regimes on the anode surface, could also enhance electron transport across the radial magnetic field. 


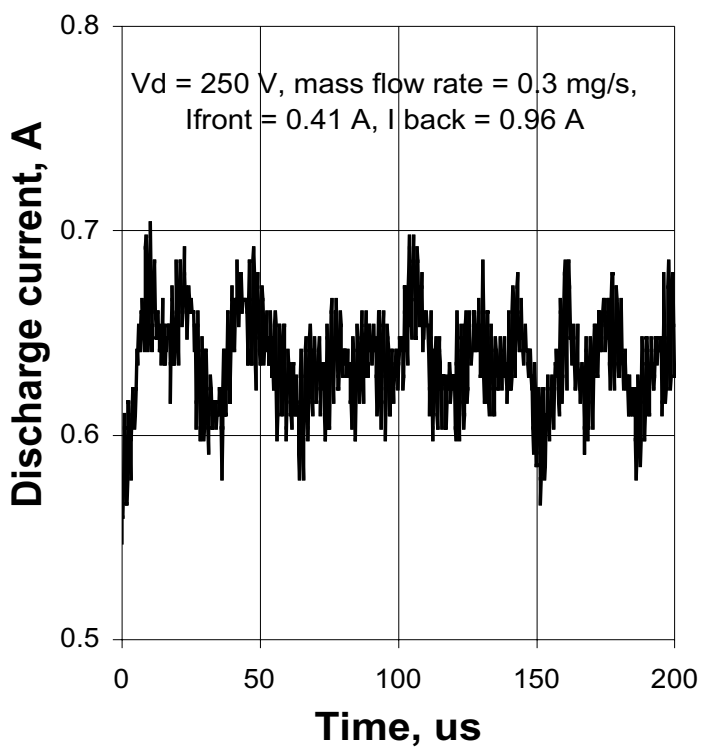

Fig. 13. Discharge current oscillations measured for the annular thruster in the stable regime.

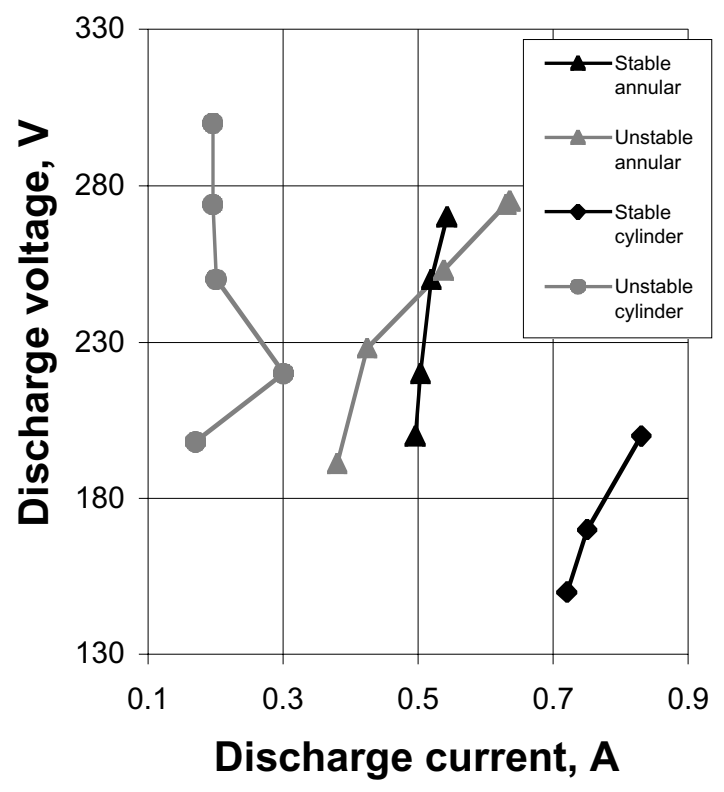

Fig. 14. Discharge voltage versus current characteristics for the $3 \mathrm{~cm}$ thruster cylindrical and annular thrusters in stable and unstable regimes at $0.3 \mathrm{mg} / \mathrm{sec}$. The cathode flow rate is $0.2 \mathrm{mg} / \mathrm{s}$.

\section{$\underline{\text { Summary }}$}

The use of a low sputtering segmented electrode made from a graphite material enabled stable and repeatable operation of the segmented electrode Hall thruster. Measurements of the plasma potential distribution revealed a strong effect of the non emissive electrode placed on the inner wall at the thruster exit on the formation of the acceleration region in the whole thruster channel and even outside it. In particular, for the segmented electrode thruster, a fraction of the voltage potential drop established in the defocusing fringing magnetic field is about 15$20 \%$ of the applied discharge voltage, while in the conventional non-segmented thruster case it achieves $40-50 \%$. Note that this substantially smaller fraction of the voltage potential drop outside the channel of the segmented thruster led only to a $10 \mathrm{deg}$ plume angle reduction as compared to the non-segmented thruster. Thus, there are other stronger mechanisms causing a large plume angle in Hall thrusters. Perhaps, some of these mechanisms can be still controlled through a precise placement of more than one electrode along the channel. Indeed, in a set of recent experiments with two segmented electrodes, which were placed at the thruster exit on the inner and outer channel walls, a $20 \mathrm{deg}$ plume reduction was measured.

To overcome scaling down difficulties caused by the beam divergence in Hall thrusters, a cylindrical geometry Hall thruster can be useful. A $3 \mathrm{~cm}$ miniaturized cylindrical thruster was developed and operated. Discharge characteristics of this thruster were comparable to those measured for the annular thruster of the same overall dimensions. Two operating modes, stable and unstable, were observed at various discharge voltages and gas flow rates in both thruster configurations. At certain conditions, a bifurcation of the thruster operation can take place. These interesting regime of the miniaturized thruster, which may be relevant to fundamental scaling down limitations of Hall thrusters, is currently being investigated. 


\section{$\underline{\text { Acknowledgment }}$}

The authors benefited from many discussions with Dr. Michael Keidar and Prof. Amnon Fruchtman. Thanks also to Mike Niemack, Sy Stange and Richard Yager for their assistance in experiments.

This work was supported by grants from New Jersey State Science and Technology Commission, AFOSR and DARPA.

\section{$\underline{\text { References }}$}

1. A. I. Morozov and V. V. Savelyev, in Review of Plasma Phsyics, edited by B.B. Kadomtsev and V. D. Shafranov, Consultants Bureau, New York, 2000, Vol. 21, p. 203.

2. V. V. Egorov, V. Kim, A. A. Semenov and I. I. Shkarban, in Ion Injectors and Plasma Accelerators, Energoizdat, Moscow, 1990, p. 56 [in Russian]

3. N. J. Fisch, Y. Raitses, L. A. Dorf and A. A. Litvak, Design and Operation of Hall Thruster with Segmented Electrode, AIAA 99-2572, Los Angeles, CA, June 1999.

4. Y. Raitses, L. A. Dorf, A. A. Litvak and N. J. Fisch, J. Appl. Phys. 88, 1263, 2000.

5. N. Fisch, Y. Raitses, L. A. Dorf and A. A. Litvak, J. Appl. Phys. 89, 2040, 2001.

6. A. Fruchtman, N. J. Fisch and Y. Raitses, Phys. Plasmas, 8, 1048, 2001.

7. Y. Raitses and N. J. Fisch, Phys. Plasmas, 8, 2579, 2001.

8. N. Matsunami et al, Eneregy Dependence of the Yelds of Ion-Induced Sputtering of Monoatomic Solids, Institute of Plasma Physics Report IPPJ-AM-32, Nagoya University, Japan, p. 27, 1983.

9. J. M. Haas, G. G. Spanjers, K. McFall, R. A. Spores, AIAA paper 98-3656, Cleveland, $\mathrm{OH}$ July 1998.

10. J. M. Haas and A. D. Gallimore, Phys. Plasmas, 8, 652, 2001.

11. R. Piejak, V. Godyak, B. Alexandrovich and N. Tishchenko, Plasma Source Sci. Technl. 7, 590, 1998.

12. D. Staack, Y. Raitses and N. J. Fisch to be submitted to Rev. Sci. Instr.

13. V. A. Rozhansky and L. D. tsendin, Transport Phenomena in Partially Ionized Gases, Gordon and Breach, Amsterdam, 2000, Chap. 3.

14. W. A. Hargus, Jr. and M. Cappelli, AIAApaper —99-2721, June 1999.

15. J. P. Boef and L. Garrigues, J. Appl. Phys., 84, 1998 


\section{External Distribution}

Plasma Research Laboratory, Australian National University, Australia

Professor I.R. J ones, Flinders University, Australia

Professor J oão Canalle, Instituto de Fisica DEQ/IF - UERJ , Brazil

Mr. Gerson O. Ludwig, Instituto Nacional de Pesquisas, Brazil

Dr. P.H. Sakanaka, Instituto Fisica, Brazil

The Librarian, Culham Laboratory, England

Library, R61, Rutherford Appleton Laboratory, England

Mrs. S.A. Hutchinson, JET Library, England

Professor M.N. Bussac, Ecole Polytechnique, France

Librarian, Max-Planck-Institut für Plasmaphysik, Germany

J olan Moldvai, Reports Library, MTA KFKI-ATKI, Hungary

Dr. P. Kaw, Institute for Plasma Research, India

Ms. P.J . Pathak, Librarian, Insitute for Plasma Research, India

Ms. Clelia De Palo, Associazione EURATOM-ENEA, I taly

Dr. G. Grosso, Instituto di Fisica del Plasma, Italy

Librarian, Naka Fusion Research Establishment, J AERI, J apan

Library, Plasma Physics Laboratory, Kyoto University, J apan

Research Information Center, National Institute for Fusion Science, J apan

Dr. O. Mitarai, Kyushu Tokai University, J apan

Library, Academia Sinica, Institute of Plasma Physics, People's Republic of China

Shih-Tung Tsai, Institute of Physics, Chinese Academy of Sciences, People's Republic of China

Dr. S. Mirnov, TRINITI, Troitsk, Russian Federation, Russia

Dr. V.S. Strelkov, Kurchatov Institute, Russian Federation, Russia

Professor Peter Lukac, Katedra Fyziky Plazmy MFF UK, Mlynska dolina F-2, Komenskeho Univerzita, SK-842 15 Bratislava, Slovakia

Dr. G.S. Lee, Korea Basic Science Institute, South Korea

Mr. Dennis Bruggink, Fusion Library, University of Wisconsin, USA

Institute for Plasma Research, University of Maryland, USA

Librarian, Fusion Energy Division, Oak Ridge National Laboratory, USA

Librarian, Institute of Fusion Studies, University of Texas, USA

Librarian, Magnetic Fusion Program, Lawrence Livermore National Laboratory, USA

Library, General Atomics, USA

Plasma Physics Group, Fusion Energy Research Program, University of California at San Diego, USA

Plasma Physics Library, Columbia University, USA

Alkesh Punjabi, Center for Fusion Research and Training, Hampton University, USA

Dr. W.M. Stacey, Fusion Research Center, Georgia Institute of Technology, USA

Dr. J ohn Willis, U.S. Department of Energy, Office of Fusion Energy Sciences, USA

Mr. Paul H. Wright, Indianapolis, Indiana, USA 
The Princeton Plasma Physics Laboratory is operated by Princeton University under contract with the U.S. Department of Energy.

\author{
Information Services \\ Princeton Plasma Physics Laboratory \\ P.O. Box 451 \\ Princeton, NJ 08543
}

Phone: 609-243-2750

Fax: 609-243-2751

e-mail: pppl_info@pppl.gov

Internet Address: http://www.pppl.gov 